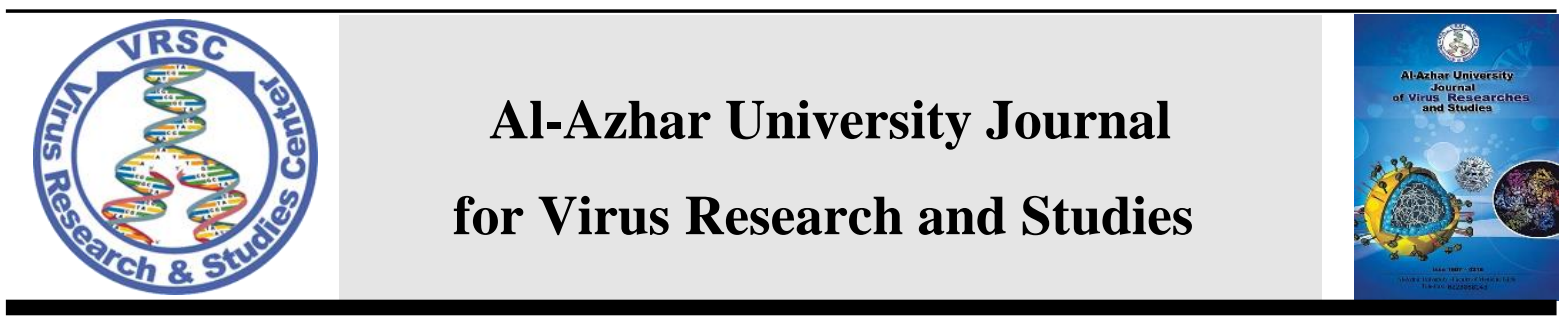

\title{
Assessment of Fibrosis After Treatment with Direct Acting Antiviral Drugs with or without Silymarin in Patients with Chronic Hepatitis C Related Liver Disease
}

\author{
Eman Rewisha*1, Tary Salman', Omkolsoum Alhaddad', Shymaa Rashad ${ }^{1}$, Gamal \\ Abo Raia ${ }^{2}$, Ahmed Abdelfattah ${ }^{1}$, Eman Abdelsameea ${ }^{1}$ and Khaled Metwally*1 \\ ${ }^{1}$ Hepatology and gastroenterology department, National Liver Institute, Menoufia \\ University, Egypt.
}

${ }^{2}$ Clinical pathology department, National Liver Institute, Menoufia University, Egypt.

*E-mail: dreman555@yahoo.co.uk

\begin{abstract}
Direct-Acting Antivirals (DAAs) are now the standard of care for management of chronic hepatitis $\mathrm{C}(\mathrm{CHC})$ infection. Patients who are treated from HCV infection with sustained virological response experience multiple health benefits, like a decrease in liver inflammation, regression of fibrosis. Aim: to evaluate change in hepatic fibrosis through liver and spleen stiffness measurements using fibroscan in relation to combination of DAAs and silymarin in chronic HCV patients. Methods: this prospective study included 300 chronic HCV patients. They were classified into group $1(n=150)$ who received DAAs and group $2(n=150)$ who received DAAs then fixed oral dose of silymarin (420 mg daily in three divided doses) for 9 months after end of treatment with DAAs. Assessment of liver and spleen stiffness were done twice by transient elastography, at time of inclusion before starting treatment and one year later. Results: Patients in group 1 and 2 achieved a significant improvement in all biochemical parameters in form of significant reduction in serum AST, ALT levels, $(p=0.001)$, significant improvement in INR $(\mathrm{p}=0.001)$ and albumin $(\mathrm{p}<0.05)$. However, there was no statistically significant difference between group 1 and 2 regarding biochemical parameters $(p>0.05)$. A statistically significant reduction in stiffness values of liver and spleen had been established in both groups. Group 2 showed a significant greater reduction in liver stiffness values compared to group1 ( $\mathrm{p}=0.007)$. Conclusion: Among chronic HCV patients, DAAs yielded a significant improvement in overall disease parameters. This improvement has shown to be significantly greater when silymarin was added to DAAs.
\end{abstract}

Keywords: Hepatitis C, Fibrosis, DAAs, Fibroscan, Stiffness, Silymarin.

\section{Introduction}

Chronic hepatitis $\mathrm{C}$ virus (HCV) infection is considered as one of the main causes of chronic liver disease worldwide. The liver insult can be ranged from minimal histological changes to different grades of liver fibrosis and cirrhosis [1]. Novel Direct-Acting Antivirals (DAAs) are now the standard of care for the management of $\mathrm{HCV}$ infection. DAAs are associated with high sustained virological response at 12 
Weeks (SVR12) [2,3]. Recent data suggests that effective DAA therapy is associated with short-term reduction of fibrosis, with unclear long-term effects [4]. Silymarin is an oral drug known by its membrane stabilizing activities and potent antioxidant capabilities. It enhances hepatocyte regeneration, reducing the inflammatory reaction and this will inhibit hepatic fibrogenesis [5]. Fibroscan (vibration-controlled transient elastography) is a novel, non-invasive technique to assess hepatic fibrosis (Liver Stiffness Measurement-LSM) and splenic stiffness measurement that has been validated in CHC. $[6,7,8,9]$.

The aim of this study is to evaluate the changes in liver fibrosis through hepatic and splenic stiffness measurements using fibroscan in relation to combination of direct acting antiviral therapy and silymarin in patients with hepatitis C related chronic liver disease.

\section{Materials and Methods}

This prospective study included 300 patients with chronic $\mathrm{HCV}$ related chronic liver disease who were recruited from the outpatient virology clinic, hepatology and gastroenterology department, National Liver Institute, Menoufia University. CHC and patients with compensated cirrhosis who had detectable HCV RNA at the baseline were treated with DAA. Successful baseline pretreatment LSM by transient elastography and baseline measurement of splenic stiffness along with measurement at 3 months after end of therapy and also at one year after completion of antiviral therapy were included in our study. Patients were excluded if they had: bilirubin $\geq 5 \mathrm{mg} / \mathrm{dl}$, co-infection with other hepatotropic viruses, levels of Aspartate Aminotransferase (AST)/ levels of Alanine Aminotransferase (ALT) $\geq 10$ times the upper limit of normal, alcohol consumption $>20 \mathrm{~g} /$ day. The presence of ascites or other co-existing causes of liver disease or decompensated cirrhosis was exclusion criteria. The study was performed in accordance with principles of Declaration of Helsinki. The study was approved by our institution's ethics committee and informed consent was taken from all studied patients. The recruitment of cases defined as being eligible to this study had been lasted from March 2017 to April 2019. Laboratory investigations in the form of liver function test as ALT, AST, bilirubin, international normalized ratio (INR), albumin, renal function tests, complete blood count (CBC) and lipid profile were done initially before starting treatment. Also, fasting blood sugar level, 2 hours post prandial blood sugar level and hemoglobin A1c were also measured in all patients to exclude presence of diabetes mellitus (DM). All studied patients underwent abdominal ultrasound examination before start of DAAs treatment to exclude presence of hepatic focal lesions and also to exclude presence of fatty liver as a cause of nonalcoholic fatty liver diseas. In this study, all oral anti HCV regimens were tailored according to National Committee for combating Hepatitis Virus (NCCVH) protocol. Three hundred patients with SVR had further classification into 2 groups. Group 1 comprised 150 patients who received oral anti HCV treatment and achieved sustained virological response. Group 2 comprised 150 patients who received oral anti HCV treatment and achieved sustained virological response $\&$ they received fixed oral dosing of silymarin $(420 \mathrm{mg}$ daily in three divided doses) for 9 months after the end of anti HCV treatment. The study adopted the following exclusion criteria: Quantification of HCV RNA level by Real time PCR was done at the beginning of treatment, after one month, at end of treatment, then 3 months after the end of treatment. Model for end stage liver disease (MELD) score [10] and ChildPugh score [11] were calculated before treatment. Assessment of fibrosis by: Fib4 score was calculated before treatment as follow: Fib-4 $=($ Age $\times$ AST $) /$ [Platelet 
count $\left(\mathrm{x} 10^{9} / \mathrm{L}\right) \mathrm{x}$ sqr (ALT)] [12]. Liver stiffness measurement by transient elastography was done twice, at the time of inclusion in the study before starting antiviral drugs and at one year after inclusion in the study. The values of liver stiffness measured by TE were interpreted to stage of fibrosis according to the following adapted form [13]: $\mathrm{F} 0=0-5.4$ kilopascal $(\mathrm{kPa}), \mathrm{F} 1=5.5$ - 6.9 KPa, F2=7 9.4 KPa, F3=9.5 - 14.4 KPa, F4=14.5 - 75 $\mathrm{KPa}$. Splenic stiffness measurements were performed using fibroscan apparatus; moreover, in agreement with technical features of fibroscan, patients with a splenic parenchymal thickness of less than $4 \mathrm{~cm}$ under the probe were excluded. The results were expressed as a median value of the total measurements in KPa. In the absence of guidelines for measurement of SS by fibroscan, the same guidelines for the measurement of LS were applied (i.e., $>10$ validated measurements, success rate $>60 \%$ and IQR $<30 \%$ ). Elastic modulus E expressed as $\mathrm{E}=3 \rho \mathrm{V} 2$, where $\mathrm{V}$ represents shear velocity and $\rho$ represents mass density (constant for tissues); the stiffer the tissue, the quick the shear wave propagates [14]. The assessment of spleen stiffness by using transient elastography was done twice for every patient with hepatitis C related chronic liver disease, at the time of inclusion in the study before starting antiviral drugs and at one year after inclusion in the study.

\subsection{Statistical analysis:}

Data were collected, tabulated, statistically analyzed using an IBM personal computer with Statistical Package of Social Science (SPSS) version 22 (SPSS, Inc, Chicago, Illinois, USA). Where the following statistics was applied: Descriptive statistics: in which quantitative data were presented in the form of mean (M), standard deviation (SD), range, and qualitative data were presented in the form numbers and percentages Analytical statistics: The used tests of significance included: Chi-square test $(\chi 2)$, Fischer exact test, Student t-test, Mann-Whitney test (nonparametric test), Wilcoxon signed rank test (nonparametric test) and McNemar's test. $\mathrm{P}$ value of $>0.05$ was considered statistically non-significant, $p$ value of $<0.05$ was considered statistically significant and $\mathrm{p}$ value of $<0.001$ was considered statistically highly significant.

\section{Results}

Total In our study, group 1 included 101 $(67.3 \%)$ males with a mean age of $50.7 \pm 11.2$ years old. While group II included $88(58.7 \%)$ males with a mean age of $48.3 \pm 10.8$ years old. No statistically significant differences were found among the two studied groups regarding their age, gender ( $\mathrm{p}=0.064 \& 0.12$ respectively).

Comparison of the baseline laboratory parameters between both groups were shown in Table 1. Patients in group 1 and 2 achieved a statistically significant improvement in all biochemical parameters in the form of significant reduction in serum AST, ALT levels and significant improvement in international normalized ratio (INR) and serum albumin level. However, there was no statistically significant difference between group 1 and 2 in respect to biochemical parameters. There was a statistically significant difference regarding the different stages of liver fibrosis measured by fibroscan before treatment and at one year after the end of treatment in group I. Reversal of fibrosis was found more in stage three and four than other stages. As regards F4 stage, $51.3 \%$ of patients before treatment reduced to be $40.7 \%$ one year after treatment and $13.3 \%$ of patients reduced to $6.7 \%$ after treatment in stage three $(\mathrm{p}<0.05)$ as shown in Table 2. There was a statistically significant difference regarding the different stages of liver fibrosis measured by fibroscan before treatment and at one year after inclusion in group II. Reversal of fibrosis was also found more in stage three and four than other stages. Fifty-seven patients $(38 \%)$ in stage four reduced to 37 $(24.8 \%)$ patients and eighteen patients 
$(12.1 \%)$ in stage three reduced to $14(9.4 \%)$ patients $(\mathrm{p}<0.05)$ as shown in Table 3 . No statistically significant differences were found among the two studied groups before treatment regarding Fib-4, liver stiffness, spleen stiffness and fibrosis stages assessed by fibroscan $(\mathrm{p}=0.073,0.060$, $0.134,0.093$ respectively) as shown in Table 4. By comparing the different means of liver stiffness values before treatment and after one year inclusion in group I, there was statistically significant decrease in their values. The mean $\pm \mathrm{SD}$ of liver stiffness value was $15.5 \pm 9.86$ and $14.4 \pm 12.0 \mathrm{kPa}$ respectively in group II ( $\mathrm{p}<0.05$ ). By comparing the different means of splenic stiffness measurements in group II, we found statistically significant differences in their values before treatment and at one year after inclusion. Splenic stiffness values decreased at one year after inclusion, as the mean $\pm \mathrm{SD}$ of splenic stiffness was $37.6 \pm 18.4 \mathrm{kPa}$ before treatment and it was $36.7 \pm 17.6 \mathrm{kPa}$ at one year after inclusion in the study in group II $(\mathrm{p}<0.05)$.

Table (1): Comparison of the baseline laboratory parameters between both groups.

\begin{tabular}{|c|c|c|c|c|}
\hline \multirow{3}{*}{ Studied variables } & \multicolumn{2}{|c|}{ Before treatment } & \multirow{3}{*}{$\begin{array}{c}\text { Mann } \\
\text { Whitney } \\
\text { test }\end{array}$} & \multirow{3}{*}{ p-value } \\
\hline & $\begin{array}{l}\text { Group I } \\
(\mathbf{N}=\mathbf{1 5 0})\end{array}$ & $\begin{array}{r}\text { Group II } \\
(\mathrm{N}=150) \\
\end{array}$ & & \\
\hline & Mean \pm SD & Mean \pm SD & & \\
\hline HB (g/dL) & $14.2 \pm 9.21$ & $14.2 \pm 8.21$ & 0.602 & 0.547 \\
\hline WBCs $x\left(10^{3} / \mu \mathrm{L}\right)$ & $6.36 \pm 2.09$ & $8.64 \pm 9.99$ & 1.41 & 0.156 \\
\hline Platelets $x\left(10^{3} / \mu \mathrm{L}\right)$ & $174.9 \pm 86.3$ & $182.8 \pm 67.8$ & 1.76 & 0.077 \\
\hline Total bilirubin(mg/dL) & $0.77 \pm 0.32$ & $0.74 \pm 0.35$ & 1.52 & 0.129 \\
\hline Albumin (g/dL) & $3.82 \pm 0.55$ & $3.82 \pm 0.45$ & 0.01 & 0.677 \\
\hline $\operatorname{AST}(\mathbf{U} / \mathrm{L})$ & $56.8 \pm 40.4$ & $54.3 \pm 41.5$ & 0.826 & 1.00 \\
\hline $\operatorname{ALT}(\mathbf{U} / \mathbf{L})$ & $60.5 \pm 44.5$ & $56.2 \pm 43.4$ & 0.985 & 0.325 \\
\hline INR & $1.60 \pm 1.31$ & $1.71 \pm 0.81$ & 1.62 & 0.104 \\
\hline Creatinine(mg/dL) & $0.88 \pm 0.78$ & $0.82 \pm 0.18$ & 0.378 & 0.795 \\
\hline FBS & $110.4 \pm 41.3$ & $103.4 \pm 30.3$ & 1.93 & 0.053 \\
\hline HBA1C & $2.65 \pm 3.44$ & $2.33 \pm 3.18$ & 0.854 & 0.393 \\
\hline Alpha fetoprotein (ng/ml) & $6.85 \pm 7.75$ & $5.58 \pm 6.71$ & 1.78 & 0.075 \\
\hline MELD & $4.22 \pm 3.55$ & $3.37 \pm 2.83$ & 1.90 & 0.057 \\
\hline
\end{tabular}

Abbreviations: N; number; $p$ value, SD; Standard deviation, AST; aspartate transaminase, ALT; alanine transaminase, $\mathrm{Hb}$; hemoglobin, WBCs; white blood cells, INR; International Normalized Ratio, MELD; Model for end stage liver disease, FBS: fasting blood sugar. 
While there was no statistically significant difference as regards mean \pm SD of Fib-4 before treatment and at one year after inclusion in group II ( $p>0.05)$. Comparing different means of liver stiffness values before treatment and after one year inclusion in group II revealed that there was statistically significant decrease in their values. The mean $\pm \mathrm{SD}$ of liver stiffness value was $14.6 \pm 11.8$ and $10.9 \pm 9.42 \mathrm{kPa}$ respectively in group II $(\mathrm{p}<$ $0.05)$. By comparing the different means of splenic stiffness measurements in group II, we found statistically significant differences in their values before treatment and at one year after inclusion. Splenic stiffness values decreased at one year after inclusion, as the mean $\pm \mathrm{SD}$ of splenic stiffness was $36.5 \pm 18.9 \mathrm{kPa}$ before treatment and it was $35.7 \pm 24.6 \mathrm{kPaat}$ one year after inclusion in the study in group II $(p<0.05)$. While there was no statistically significant difference as regards mean \pm SD of Fib-4 before treatment and at one year after inclusion in group II $(p>0.05)$.
Upon comparing group1who received anti HCV treatment alone with group 2 who received silymarin for 9 months after end of anti HCV treatment, there were no statistically significant differences between both groups in respect to the mean \pm SD of total bilirubin, indirect bilirubin, serum albumin, AST, ALT, INR and serum creatinine ( $p>0.05$ ). As shown in Table 5., no statistically significant differences were found between the two studied groups regarding Fib-4 and splenic stiffness ( $p$ $>0.05$ ). By comparing the different means of liver stiffness values between the two studied groups at one year after inclusion, we found that, statistically significant differences were found between the two studied groups Table 5.The mean \pm SD of liver stiffness value was $14.4 \pm 12.0$ and $10.9 \pm 9.42 \mathrm{kPa}$ in group I and group II respectively $(p=0.007)$. Also, we found that there was statistically significant difference between the two studied groups regarding the different stage of liver fibrosis $(\mathrm{p}=0.031)$.

Table (2): Changes in values of the liver stiffness pre-treatment and at one year post inclusion in the study in group $\mathrm{I}(\mathrm{N}=150)$.

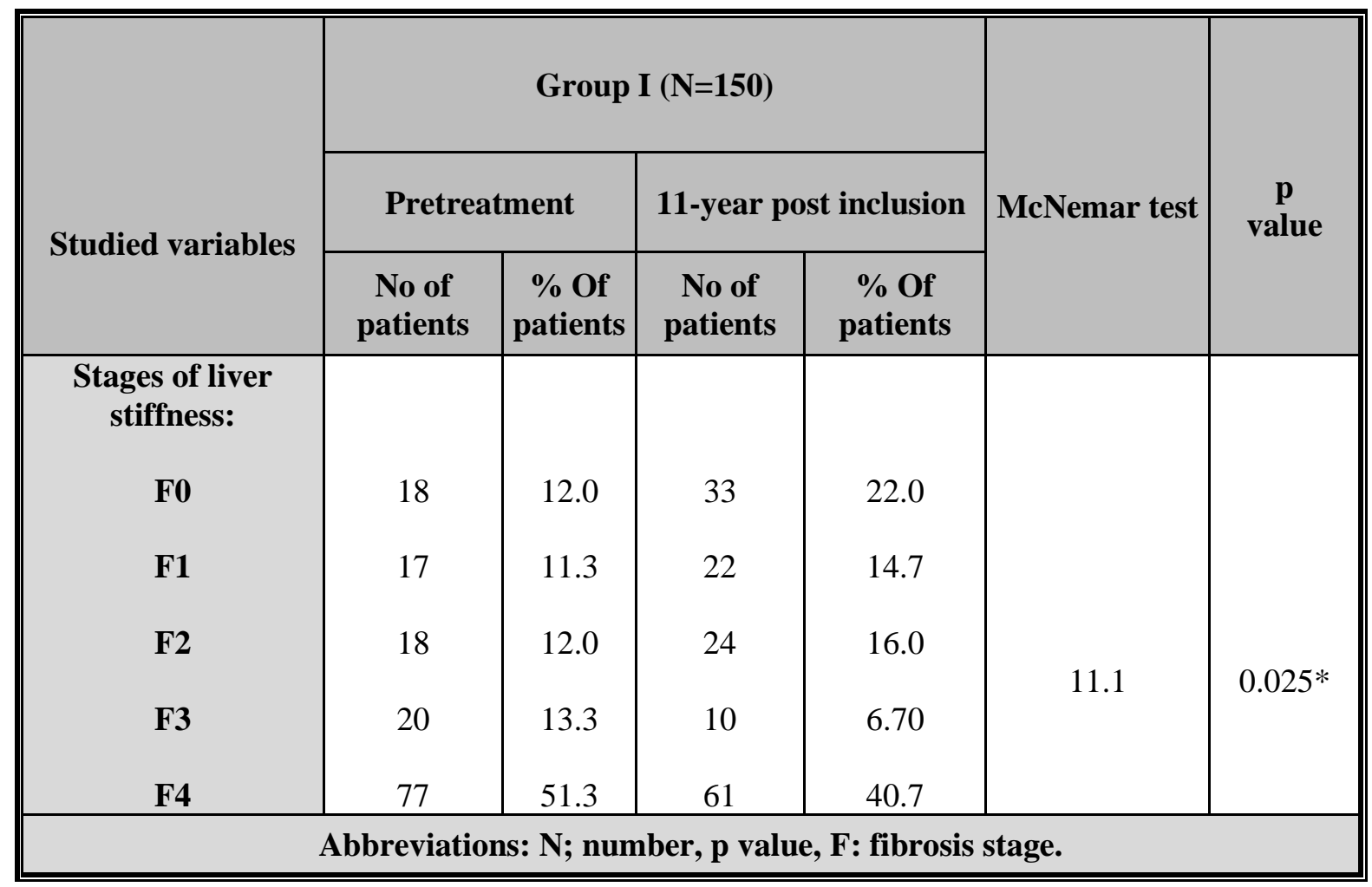


Table (3): Changes in values of liver stiffness pre-treatment and at one year post inclusion in the study in group II $(\mathrm{N}=150)$.

\begin{tabular}{|c|c|c|c|c|c|c|}
\hline \multirow{3}{*}{ Studied variables } & \multicolumn{4}{|c|}{ Group I (N=150) } & \multirow{3}{*}{ McNemar test } & \multirow{3}{*}{$\begin{array}{c}\mathbf{p} \\
\text { value }\end{array}$} \\
\hline & \multicolumn{2}{|c|}{ Pretreatment } & \multicolumn{2}{|c|}{ 11-year post inclusion } & & \\
\hline & $\begin{array}{c}\text { No of } \\
\text { patients }\end{array}$ & $\begin{array}{c}\% \text { Of } \\
\text { patients }\end{array}$ & $\begin{array}{c}\text { No of } \\
\text { patients }\end{array}$ & $\begin{array}{c}\% \text { Of } \\
\text { patients }\end{array}$ & & \\
\hline \multicolumn{7}{|l|}{$\begin{array}{l}\text { Stages of liver } \\
\text { stiffness: }\end{array}$} \\
\hline Fo & 31 & 20.8 & 40 & 26.8 & & \\
\hline F1 & 20 & 13.4 & 36 & 24.0 & \multirow{4}{*}{10.4} & \multirow{4}{*}{$0.032 *$} \\
\hline F2 & 24 & 16.1 & 23 & 15.4 & & \\
\hline F3 & 18 & 12.1 & 14 & 9.40 & & \\
\hline F4 & 57 & 38.0 & 37 & 24.8 & & \\
\hline \multicolumn{7}{|c|}{ Abbreviations: N; number, p value, $F$ : fibrosis stage. } \\
\hline
\end{tabular}

Table (4): Comparison of the pretreatment Fib-4, stiffness values of the liver and spleen between both groups $(\mathrm{N}=300)$.

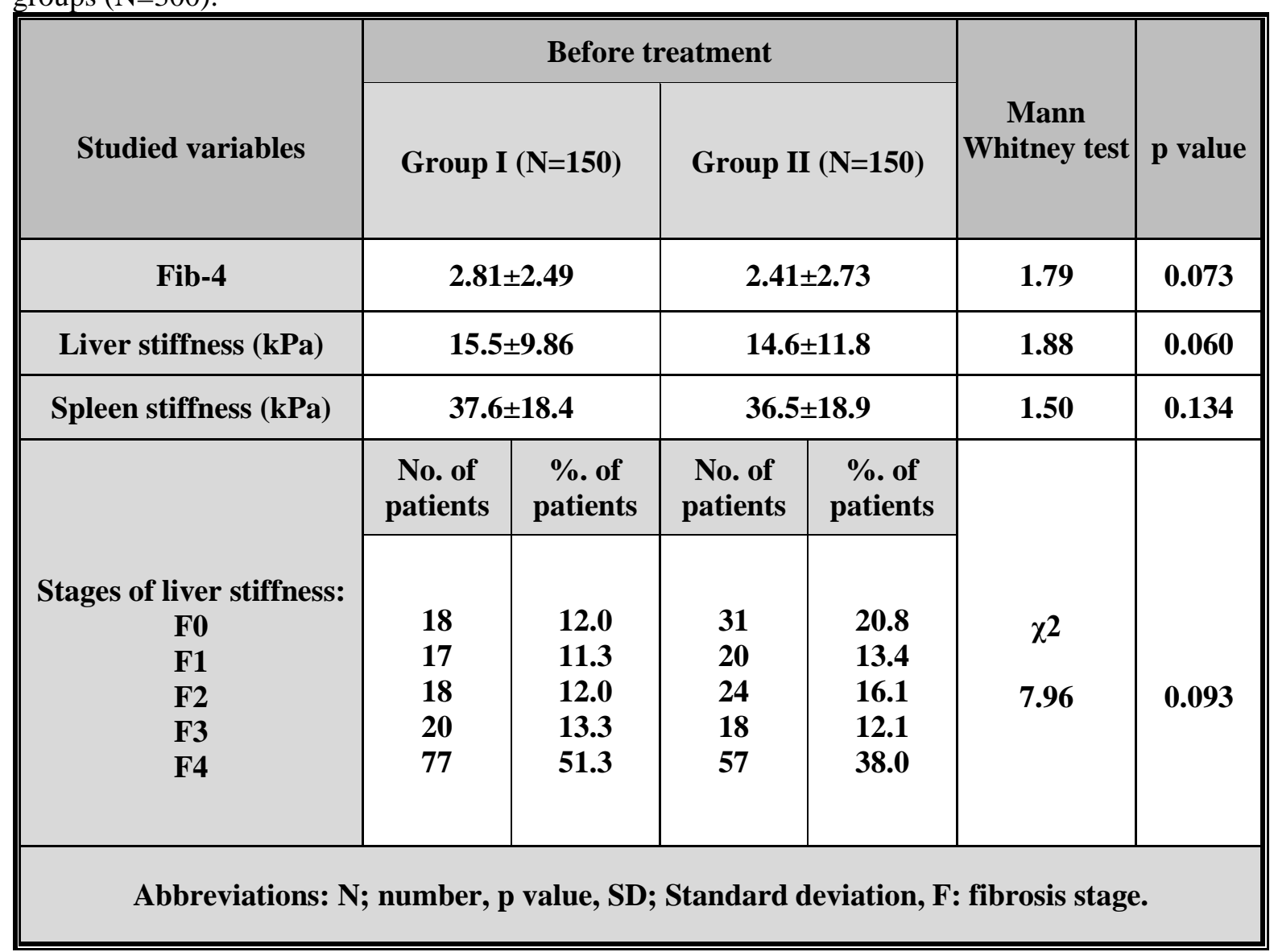


Table (5): Comparison of Fib-4, stiffness values of the liver and spleen among one year after inclusion among the two studied group $(\mathrm{N}=300)$.

\begin{tabular}{|c|c|c|c|c|c|c|}
\hline \multirow[b]{2}{*}{ Studied variables } & \multicolumn{4}{|c|}{1 year after treatment } & \multirow{2}{*}{$\begin{array}{c}\text { Mann } \\
\text { Whitney test }\end{array}$} & \multirow[b]{2}{*}{$\begin{array}{c}\mathbf{P} \\
\text { Value }\end{array}$} \\
\hline & \multicolumn{2}{|c|}{ Group I (N=150) } & \multicolumn{2}{|c|}{ Group II (N=150) } & & \\
\hline Fib-4 & \multicolumn{2}{|c|}{$2.76 \pm 2.46$} & \multicolumn{2}{|c|}{$2.40 \pm 2.74$} & 1.36 & 0.103 \\
\hline $\begin{array}{c}\text { Liver stiffness (Mean } \\
\pm \text { SD) }\end{array}$ & \multicolumn{2}{|c|}{$14.4 \pm 12.0$} & \multicolumn{2}{|c|}{$10.9 \pm 9.42$} & 2.71 & $0.007 *$ \\
\hline $\begin{array}{c}\text { Spleen stiffness (Mean } \\
\pm \text { SD }\end{array}$ & \multicolumn{2}{|c|}{$36.7 \pm 17.6$} & \multicolumn{2}{|c|}{$35.7 \pm 24.6$} & 0.681 & 0.496 \\
\hline \multirow{2}{*}{$\begin{array}{l}\text { Liver stiffness } \\
\text { stages: }\end{array}$} & $\begin{array}{c}\text { No. of } \\
\text { patients }\end{array}$ & $\begin{array}{c}\% \text { Of } \\
\text { patients }\end{array}$ & $\begin{array}{c}\text { No. of } \\
\text { patients }\end{array}$ & $\begin{array}{c}\% \text { Of } \\
\text { patients }\end{array}$ & \multirow[b]{2}{*}{$\begin{array}{c}\chi^{2} \\
10.6\end{array}$} & \multirow[b]{2}{*}{$\mathbf{0 . 0 3 1} *$} \\
\hline & $\begin{array}{l}33 \\
22 \\
24 \\
10 \\
61\end{array}$ & $\begin{array}{l}22.0 \\
14.7 \\
16.0 \\
6.70 \\
50.7\end{array}$ & $\begin{array}{l}40 \\
36 \\
23 \\
14 \\
37\end{array}$ & $\begin{array}{l}26.8 \\
24.0 \\
15.4 \\
9.40 \\
24.8\end{array}$ & & \\
\hline ions & n & 51 & - & $\overline{7}$ & stag & \\
\hline
\end{tabular}

\section{Discussion}

Improvement of existing liver fibrosis is a major cause for treatment of $\mathrm{CHC}$ with DAAs. Serial liver biopsies in those patients have risk of many complications so non-invasive techniques to assess stage of fibrosis prior to and after end of $\mathrm{HCV}$ therapy are widely used. Experience with patients and their follow up after successful DAA treatment is still limited and the significance of estimated reduction in liver fibrosis measured non-invasively is of clinical importance. TE values could become a basis for further patient follow up and surveillance after eradication of $\mathrm{HCV}$
[15]. A study done by Gyanranjan et al demonstrated that in a large number of predominantly genotype $3 \mathrm{CHC}$ patients treated with generic sofosbuvir-based regimens, there was an observed decrease in values of LSM post DAA treatment. This decline reflects a decrease in hepatic fibrosis. In contrast, there was an increase in values of controlled attenuation parameter (CAP) representing hepatic steatosis after therapy [16]. HCV management has undergone paradigm shift from interferon-based regimens that were associated with low SVR rates to oral DAAs, which are associated with very high SVR12 rates. Although considered to be safe in the short term, there is no available 
data regarding the long-term effects of oral DAAs. The recent guidelines recommend DAAs for all chronic HCV positive patients, irrespective of underlying fibrosis.15,17 Furthermore, World Health Organization has recently launched a drive to eliminate viral hepatitis by 2030. [17] The majority of patients in our study were male $(63 \%)$. In their systematic review and meta-analysis, Mohamoud and colleagues showed that higher prevalence of chronic HCV infection was observed in males [18]. In the present study, $93 \%$ of patients achieved SVR after treatment with negative HCV PCR and only 25 patients $(7.7 \%)$ relapsed. In agreement to this finding, Yek and colleagues conducted retrospective observational study included all patients undergoing $\mathrm{HCV}$ treatment with DAAbased therapy. The authors reported a SVR of $95 \%$ for the patients who were followedup [19]. In the present study, all patients achieved the SVR after treatment showed a statistically significant improvement in biochemical parameters in form of significant reduction in serum AST, ALT level and significant improving in INR and serum albumin level. Also, it showed a statistically significant increase in serum total bilirubin level after end of DAAs regimens then return to normal at one year after inclusion in the study. In the present study, there was a statistically significant reduction in serum ALT and AST level after the end of treatment in both groups. However, there was no statistically significant difference in AST and ALT between the two studied groups who received DAAs and who received silymarin for 9 months after end of treatment with DAAs. These results came in concordance with Fried and colleagues' trial which showed no statistically significant changes in AST and ALT values after Silymarin [20]. TE is an ultrasound-based noninvasive method and characterized by the material's strain response to external stress according to the principle of Hooke's law [21].TE is accurate for staging liver fibrosis and can be used for prediction of mortality and severe outcome in patients with chronic liver diseases [22]. With regard to our primary outcomes, DAAs plus silymarin combination and DAAs therapy alone resulted in statistically significant reduction in liver and spleen fibrosis scores. In line with our findings, Tada and colleagues in 2017 performed a prospective study to evaluate the sequential changes in liver stiffness using shear wave elastography in patients with $\mathrm{HCV}$ who received DAAs therapy. The results showed that early improvement of liver stiffness starts during the administration of DAAs in patients who achieve SVR, and this effect is particularly pronounced in patients with progressive liver fibrosis [23]. Similarly, Kobayashi and colleagues in 2018 assessed liver stiffness on 57 patients with HCV who received DAAs therapy and achieved SVR; liver stiffness was evaluated with TE [24]. The median liver stiffness values changed significantly after DAAs treatment. In a similar vein, Ogasawara and colleagues showed a significant improvement in liver stiffness in response to daclatasvir and asunaprevir dual therapy. Notably, patients who received DAAs plus silymarin combination showed a statistically significant greater reduction in liver and spleen stiffness stages compared to patients who received DAAs alone. To the best of our knowledge, this is the first clinical trial to assess the role of silymarin after DAAs in patients with chronic HCV [25]. In concordance with our findings, Tada and colleagues suggest that early improvement of liver stiffness starts during the administration of DAAs in patients who achieve SVR, and this effect is particularly pronounced in patients with progressive liver fibrosis [25]. Several studies have indicated that the liver stiffness value can be significantly influenced by major changes in aminotransferases level in patients with chronic viral hepatitis and that LSM is unreliable for diagnosing underlying liver fibrosis in patients with acute liver damage [26]. Rewisha et al. reported a significant 
decrease in mean \pm SD value of LSM from $13.91 \pm 6.7 \mathrm{kPa}$ at baseline (in acute hepatitis phase) to $7.7 \pm 3.08 \mathrm{kPa}$ after resolution of hepatitis $(p<0.01)$ [27]. Liver stiffness measurement has some weaknesses represented as over reading in the state of liver cell inflammation, cholestasis and steatosis. The measurement of spleen stiffness can be a good opportunity to elude such weaknesses [28]. Our results at the start of treatment showed that, splenic stiffness measured by TE was increased as liver disease progresses. There was a significant positive correlation between LS and splenic stiffness. These finding were in agreement with Rewisha and her colleague's studied evaluation of $\mathrm{TE}$ of the liver and spleen in assessment of disease severity in patients with chronic HCV Infection. They found that there was a significant positive correlation between LS and splenic stiffness. Spleen stiffness

\section{References}

1- Polaris Observatory HCV Collaborators. Global prevalence and genotype distribution of hepatitis $\mathrm{C}$ virus infection in 2015: a modelling study. Lancet Gastroenterology Hepatology 2017; 2 (3):161-76.

2- Falade-Nwulia O., Suarez-Cuervo C., Nelson D.R., et al. Oral direct-acting agent therapy for hepatitis $\mathrm{C}$ virus infection: a systematic review. Ann Intern Med. 2017;166(9):637-648.

3- Gupta S., Rout G., Patel A.H. Efficacy of generic oral directly acting agents in patients with hepatitis $C$ virus infection. J Viral Hepat. 2018;25(7):771-778.

4- Poynard T., Moussalli J., Munteanu M. Slow regression of liver fibrosis presumed by repeated biomarkers after virological cure in patients with chronic hepatitis C. J Hepatol. 2013;59(4):675683. value at cut-off $37.8 \mathrm{kpa}$ could differentiate those with fibrosis stage F3 versus those with cirrhosis with $80.0 \%$ sensitivity, $76.4 \%$ specificity, $79.0 \%$ PPV $77.5 \%$ NPV and $78.3 \%$ Accuracy [29].

\section{Conclusion}

Among chronic HCV patients, DAAs yielded a significant improvement in overall disease parameters. This improvement has shown to be significantly greater when silymarin was added to DAAs. Spleen stiffness along with liver stiffness measurement could be a suitable noninvasive procedure for assessment of disease severity and progression in chronic hepatitis $\mathrm{C}$ patients. Patients, who are cured of their HCV infection, should be do liver stiffness measurement by fibroscan at least one year after treatment.

5- Feher $\mathbf{J}$ and Lengyel G. Silymarin in the prevention and treatment of liver diseases and primary liver cancer. Curr. Pharmcology Biotechnology 2012; 13:210-17.

6- Sasso M., Tengher-Barna I., Ziol M. Novel controlled attenuation parameter for noninvasive assessment of steatosis using Fibroscan (®): validation in chronic hepatitis C. J Viral Hepat. 2012;19(4):244-253.

7- Karlas T., Petroff D., Sasso M. Individual patient data meta-analysis of controlled attenuation parameter (CAP) technology for assessing steatosis. J Hepatol. 2017;66(5):1022-1030.

8- Poynard T., de Ledinghen V., Zarski J.P. Relative performances of FibroTest, Fibroscan, and biopsy for the assessment of the stage of liver fibrosis in patients with chronic 
hepatitis $\mathrm{C}$ : a step toward the truth in the absence of a gold standard. J Hepatol. 2012;56(3):541-548.

9- Rout G., Kedia S., Nayak B. Controlled attenuation parameter for assessment of hepatic steatosis in Indian patients. J Clin Exp Hepatol. 2018 https://doi.org/10.1016/j.jceh.2018.02. 010.

10-Malinchoc M, Kamath PS, Gordon FD,et al.A model to predict poor survival in patients undergoing transjugular intrahepatic portosystemic shunts. Journal of Hepatology 2000; 31(4): 864-871.

11- Pugh RNH, Murray-Lyon IM, Dawson $\mathrm{JL}$, Pietroni MC, et al.Transection of the oesophagus for bleeding oesophageal varices. Br J Surg. 197360 (8):646-9.

12-Sterling LK, Lissen E, Clumeck N, et al. APRICOT Clinical Investigators: Development of a simple noninvasive index to predict significant fibrosis in patients with $\mathrm{HIV} / \mathrm{HCV}$ coinfection. Hepatology 2006; 43 (6): 1317-25.

13-Vergniol J, Foucher J, et al.Noninvasive tests for fibrosis and liver stiffness predict 5-year outcomes of patients with chronic hepatitis $\mathrm{C}$. Journal of Gastroenterology 2011; 140 (7):1970-9.

14- Bachofner JA, Valli PV, Kröger A, et al. Direct antiviral agent treatment of chronic hepatitis $\mathrm{C}$ results in rapidregression of transient elastography and fibrosis markers fibrosis-4 score and aspartate aminotransferase-platelet ratio index. Liver Int. 2017 Mar; 37(3):369-376. doi: 10.1111/liv.13256.
15-El Saadany S, Soliman H, Ziada DH, Hamisa M, et al. Fibroscan versus liver biopsy in the evaluation of response among the Egyptian HCV infected patients to treatment. The Egyptian Journal of Radiology andNuclear Medicine 2016;47: 1-7.

16- Gyanranjan R, Baibaswata N, Arpan H, et al. Therapy with oral directly acting Agents in hepatitis infection is associated with reduction in fibrosis and increase in hepatic steatosis on transient elastography. J Clin Exp Hepatol 2019 Mar-Apr, 9(2); 207 - 14.

17- Towards elimination of viral hepatitis by 2030. Lancet. 2016; 388(10042):308.

18- Mohamoud Y, Mumtaz G, Riome S,et al.The epidemiology of Hepatitis C virus in Egypt: a systematic review and data synthesis. BMC Infect Dis2013 Jun 24; 13:288. doi: 10.1186/14712334-13-288.

19- Yek C, de la Flor C, Marshall J, Zoellner $\mathrm{C}$, et al. Effectiveness of direct- acting antiviral therapy for hepatitis $\mathrm{C}$ in difficult-to-treat patients in a safety-net health system: A retrospective cohort study. BMC Med. 2017; 15:0969-3.

20- Fried MW, Navarro VJ, Afdhal N,et al.Silymarin in NASH and C Hepatitis (SyNCH) Study Group.Effect of silymarin (milk thistle) on liver disease in patients with chronic hepatitis $\mathrm{C}$ unsuccessfully treated with interferon therapy: a randomized controlled trial. JAMA 2012;308 (3):274-82.

21- Cui XW, Friedrich-Rust M, De Molo C, et al. Liver elastography, comments on EFSUMB elastography guidelines 2013. World Journal of 
Gastroenterology 2013; 19 (38):6329_ 47.

22- Singh S, Facciorusso A, Loomba R, et al. Magnitude and Kinetics of Decrease in Liver Stiffness After Antiviral Therapy in Patients with Chronic Hepatitis C: A Systematic Review and Meta-analysis.

Clinical Gastroenterology Hepatology 2017; 4:038.

23- Tada T, Kumada T, Toyoda H, et al. Improvement of liver stiffness in patients with hepatitis $C$ virus infection who received direct-acting antiviral therapy and achieved sustained virological response. Journal Gastroenterology Hepatology 2017; 32:1982-8.

24- Kobayashi N, Iijima H, Tada T, et al. Changes in liver stiffness and steatosis among patients with hepatitis $\mathrm{C}$ virus infection who received direct-acting antiviral therapy and achieved sustained virological response. Eurobin Journal Gastroenterology Hepatology 2018:1-1106.

25- Ogasawara N, Kobayashi M, Akuta N, et al. Serial changes in liver stiffness and controlled attenuation parameter following direct-acting antiviral therapy against hepatitis $\mathrm{C}$ virus genotype 1b. Journal Medicine Virology 2018;90:313-9.

26- Arena U, Vizzutti F, Corti G, et al. Acute viral hepatitis increases liver stiffness values measured by transient elastography. Hepatology 2008; 47:380-4.

27-Rewisha E, Badran H, Gamil K, Metwally $\mathrm{K}$, et al. Increased liver stiffness measurement values using transient elastography in Egyptian patients with acute viral hepatitis. Gastroenterol Hepatol Open 2016. 5 (3), 00145.

28- Fraquelli M, Giunta M, Pozzi R, et al. Feasibility and reproducibility of spleen transient elastography and its role in combination with liver transient elastography for predicting the severity of chronic viral hepatitis. Journal Viral Hepatology 2014; 21:90-8.

29- Rewisha EA, Elsabaawy MM, Alsebaey A, et al., Evaluation of Liver and Spleen Transient Elastography in the Diagnosis of Esophageal Varices. Journal Gastrointestinal Disorder Liver Function. 2016;2(3):1-6. 